\title{
Mobile Augmented Reality and Outdoor Education
}

Mattias Arvola, Inger Edfors Fuchs, Ingemar Nyman and Anders Szczepanski

The self-archived preprint version of this journal article is available at Linköping University Institutional Repository (DiVA):

http://urn.kb.se/resolve?urn=urn:nbn:se:liu:diva-177595

N.B.: When citing this work, cite the original publication.

Arvola, M., Edfors Fuchs, I., Nyman, I., Szczepanski, A., (2021), Mobile Augmented Reality and Outdoor Education, Built Environment, 47(2), 223-242. https://doi.org/10.2148/benv.47.2.223

Original publication available at:

https://doi.org/10.2148/benv.47.2.223

Copyright: Alexandrine Press

http://www.alexandrinepress.co.uk/ 


\title{
Mobile Augmented Reality and Outdoor Education
}

\author{
Mattias Arvola, Inger Edforss Fuchs, Ingemar Nyman and Anders Szczepanski \\ Contact: Mattias Arvola, mattias.arvola@liu.se
}

This paper describes a research project that explored the use of mobile augmented reality combined with outdoor education in a Swedish primary school. Special attention was paid to mobile augmented reality (AR). Project documentation and communication were reviewed, three iterations of design and usability evaluations of the Minnesmark mobile AR platform was made. Observations and interviews were held with teachers and students. The results describe early experiments, and both the opportunities and challenges that faced the participating teachers. The opportunities included connecting the outdoor learning environment and the indoor learning environment, directing the students' focus, posing questions and affording actions, rendering symbols and timelines visible, providing a point of entry to the context and the narrative, and facilitating conceptualization. Challenges concerned how to make pedagogical use of the landscape, producing or choosing content, structuring processes, setting up student groups, and aligning activities and content with learning objectives. It is concluded that the teachers and the students used the mobile augmented reality to make places in the local environment, outside the classroom, the starting point to increase the authenticity of the teaching.

The aim of the VASS project, which ran from 2012 to 2015, was to explore how to make use of new technology (mobile augmented reality in particular) combined with outdoor education in the context of a Swedish primary school with teachers and students aged of ten to thirteen (years 4-7). VASS is an acronym in Swedish for 'the virtual world meets the authentic world in sensuous and integrated learning' (virtuell värld möter autentisk värld $i$ ett sinnligt, samlat lärande), which worked as a vision for what we tried to do in the project. Issues that formed the starting point for the project were if we could get more students to find the learning situation meaningful; if we could use the outdoor learning environments to widen the students' awareness of the local environment and society; if we could weave together facts, understanding, skills and familiarity in the learning; and if we could develop an environmental perspective with sustainable development in our teaching? A priority was how places in our local environment could be used in combination with new technology, to promote the students' abilities and to make the learning more authentic.

During the project we also extended our own mobile augmented reality (AR) platform, called Minnesmark, with the aim of investigating how the experience of a place can be augmented by mobile computing. Research has indicated that

Arvola, M., Edforss Fuchs, I., Nyman, I., and Szczepanski (2021) Mobile augmented reality and outdoor education. Built Environment, 47(2), pp. 232-251. https://doi.org/10.2148/benv.47.2.223 PUBLISHER: ALEXANDRINE PRESS 
augmented reality can be used to connect virtual and real world and enrich exploration (Huang et al., 2016). Figure 1 gives an example of how Minnesmark was used at the oldest building in Helsingborg, where they could hear the sound of horses and carriages students and got the question of why Henckel built his yard in the middle of the intersection. The students went in and around this corner of the block and thought about whether this would be possible today, and how people in the second half of the seventeenth century might have reacted when their nearest way to the well was cut off. The questions were initiated outdoors and followed up in the classroom.

\section{Background}

The close and frequent contact with the outdoor environment in school is central for learning about sustainability, as well as other subjects, and it is well-established that outdoor education can complement classroom learning (e.g. Dahlgren and Szczepanski, 1998; Løvlie, 2007; Fägerstam, 2012; Szczepanski and Andersson, 2016). Research has also shown how mobile technology can be used both inside and outside the classroom (e.g. Jeng et al., 2010; Sollervall et al., 2012, Bouvin et al., 2005). Outdoor place-based education focuses on a student's local community and environment as both a source of information and place of learning (Løvlie, 2007).

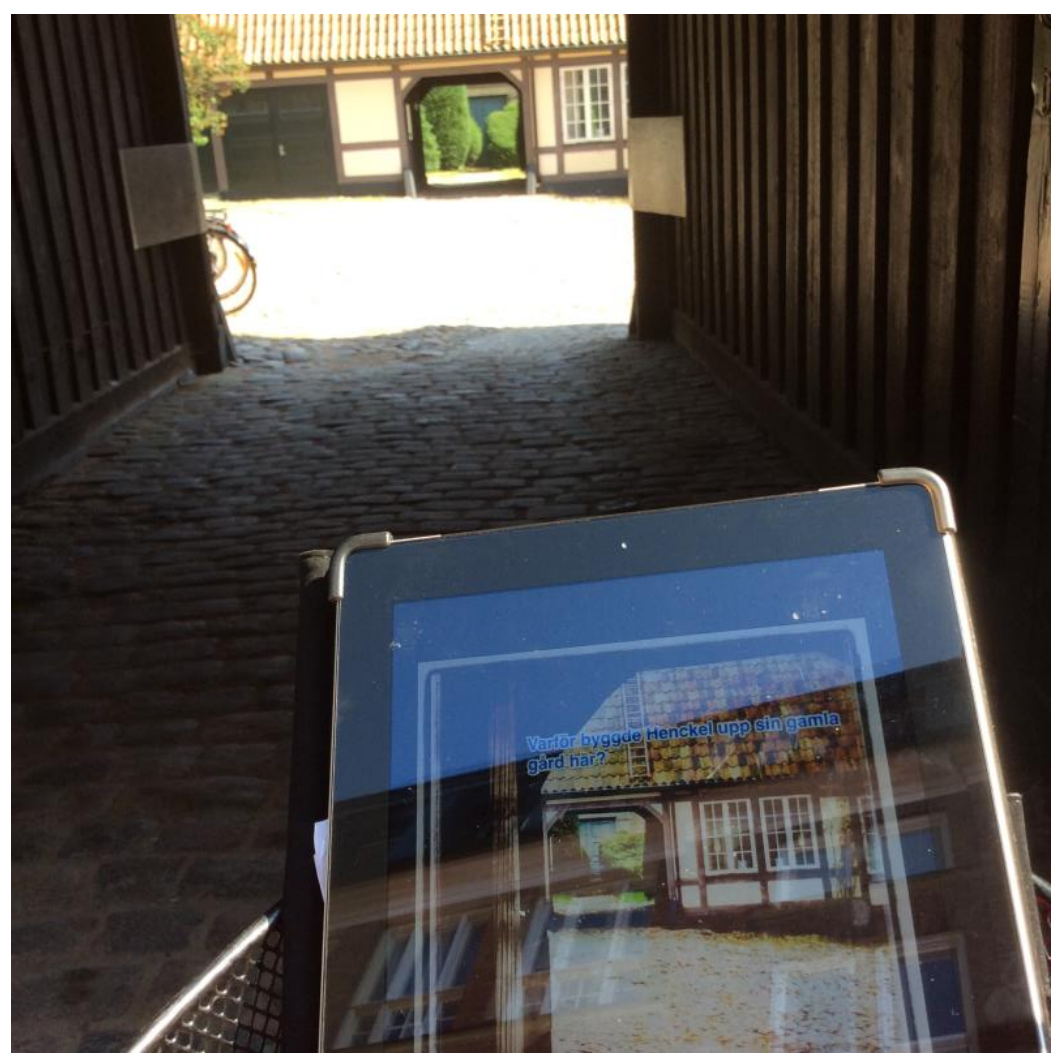

Figure 1. Minnesmark used to ask a question near the oldest house in Helsingborg. 
It also highlights that we do not only learn by seeing and hearing, but also by smelling, feeling, tasting, and touching (Dahlgren and Szczepanski, 1998). The outdoor educational approach means that learning is connected to authentic situations and environments in an interaction between experience, reflection, and knowledge with a focus on posing new questions.

There are four central components to outdoor education: the sensory experience itself; learning through this experience; the authentic place where the learning activity that constitutes the experience occurs; and finally, reflecting on the experience in an interplay with text-based learning in a classroom context (Fägerstam, 2012). Regular physical activity in outdoor learning environments during the school day has positive effects on skills, memory, learning ability, academic performance, and school results (State Education and Environment Roundtable, 2000; Dillon et al., 2007; Faskunger et al., 2018). Given this, it seems strange that outdoor education is not practiced more widely, but barriers such as lack of equipment and teachers' lack of confidence in methods and techniques stand in its way (Fägerstam, 2012; Dillon et al., 2007).

The functionality of mobile devices may include the ability to provide locationbased learning materials, to communicate with others, and take and upload pictures, for example as a record of the students' problem-solving strategies (Bouvin et al., 2005; Jeng et al., 2010; Sollervall et al., 2012). Tools such as these can improve collaboration as well as exploration and collection and sharing of information, and thus facilitating problem-solving and meaning making (Liu et al., 2009; Fitz Gerald et al., 2012; Zimmerman and Land, 2014). Mobile technology can be used to investigate the outdoor environment, but it is necessary to consider how to introduce the students to the outdoor activity, how to structure face-to-face collaboration, and what the role of the teacher is (Eliasson, 2013). It is important, for example, that the teacher directs the focus of the learning activity to objects or aspects of relevance in a place (Zimmerman and Land, 2014). Otherwise mobile technology may become an object in itself and students use it in unintended ways (Nouri and Cerratto-Pargman, 2015).

A particular kind of digital mobile technology, 'mobile augmented reality', can be of specific interest to outdoor education. Augmented reality makes it possible to overlay virtual objects and events onto the real-world places, and present information directly to the user in relation to his or her actual physical environment. For instance, augmented reality applications can be used to give instructions and overlay information directly in the user's fi eld of view. Augmented reality can be either location aware or vision-based, i.e. it presents media either as the user moves around in an area or as the user points the camera toward an object (Dunleavy and Dede, 2014). Over the last decade, the number of available mobile augmented reality applications has greatly increased, but the idea is not new (e.g., Henrysson et al., 2005; Schmalstieg and Wagner, 2007).

Mobile augmented reality experiences, for example in the form of treasure hunts, can be used for learning and to teach students about historical and cultural events 
or environmental issues (Billinghurst and Dünser, 2012; Klopfer and Squire, 2008; Wu et al., 2010; Arvola et al., 2012; Arvola and Holm, 2014; Liu et al., 2009; Nilsson et al., 2012; Wu et al., 2010). Location-based games and treasure hunts can also contribute to connectedness to nature (Schneider and Schaal, 2018). Augmentations can be used to provide alternative views on the physical world (Ducasse, 2020). For example, the time can be changed, the scale can be zoomed, and things that are invisible can be visualized or made perceivable in other ways. Furthermore, connections between different levels of analysis can be made (e.g. political, societal, biological, ecological). Outdoor scientific inquiry can also be facilitated by mobile augmented reality (Rogers et al., 2004; Zimmerman and Land, 2014). An evaluation of a mobile augmented reality application for investigation of climate change showed that students can make connections between observations in their virtual (digital) environment, their authentic (physical) environment, and subjects in their curriculum (Smørdal et al., 2016). Experiences from using a mobile urban drama for outdoor education suggests that a narrative structure, which places assignments into a meaningful context, can support learning (Hansen et al., 2010). One study indicates that students' conceptual understanding is related to their level of immersion (Georgiou and Kyza, 2018). Low intensity movement can also contribute to engagement and can thus be used as a motivating factor (Arvola and Holm, 2014). In general, experience from these projects has indicated that mobile augmented reality has potential for outdoor education. One of the main advantages of augmented reality is that it encourages taking new perspectives, and invites spatial, temporal and contextual exploration and conceptualization.

A list of requirements for augmented reality in education would, for example, include possibilities for teachers and students to set up and edit vision-based and location-based augmented reality experiences; maps, user archives and libraries of re-usable digital objects; abilities to link to media on the web; possibilities of assigning different participants to different roles; different ways of triggering digital objects; ability to set up assessments and assignments, saving data, managing device-to-device communication; and integration with social networks (Dunleavy and Dede, 2014).

However, mobile augmented reality in education involves challenges (Fitz Gerald et al., 2012), for instance positioning systems in mobile phones and tablets are sometimes inaccurate and internet connections are lost (Koutromanos et al., 2018). Also, the novelty of the technology can interfere with the learning: students may focus the technology rather than the learning objective (Nouri and CerrattoPargman, 2015). The complexity of the technology should therefore not go beyond what is needed (Kljun et al., 2020) and it is important that the teachers first consider the learning objectives before deciding how to achieve them (Fitz Gerald et al., 2012).

While a number of investigations into the educational use of mobile augmented reality have been made, the purpose of this action research study is to explore how to make use of mobile augmented reality combined with outdoor education in the 
context of a Swedish primary school with teachers and students in the age of ten to thirteen. There is a need for the research that not only furthers an academic research agenda, but also supports educators in using the technologies (Kljun et al., 2020).

\section{Method}

The research question addressed in this participatory action research (Whyte, 1991) was how to make use of mobile augmented reality combined with outdoor education. The project started in 2012 and ended in 2015 where primary school teachers together with researchers jointly searched for problems, interpretations, courses of action, and meaningful concepts relating to combinations of outdoor education and new technology.

\section{Roles of the Participatory Action Researchers}

Besides investigating the project, the first author of this paper facilitated discussion and introduced suggestions to new technologies and their potential use. He also led the further development of the technological platform that was used in the project, to make it useful and usable for the teachers, while also studying its use. The second author, a practicing teacher, was project manager. She experimented with the ideas of the project in her own teaching practice and involved other teachers intermittently in different workshop activities. The third author worked at an activity centre that supported local schools in their teaching of environmental issues and sustainability using hands-on experience-based teaching methods relating facts, understanding, skills, and familiarity to each other. The fourth author reviewed the project from the perspective of research on outdoor education and participated as an advisor responsible for the overall qualitative evaluation interviews.

\section{Procedure}

Notes were taken at seven project workdays and email communication was monitored during the project (419 email messages in total). The project documentation was also reviewed. Observations and interviews were conducted at three outdoor classes with 5 th graders at the primary school and at the activity centre for environment and sustainability issues: (1) outdoor education for students in the 5 th grade who were using mobile technology at the school; (2) a water lesson with $5^{\text {th }}$ grade students at the activity centre; and (3) outdoor food preparation at the activity centre. It is generally accepted that it is preferrable to use both observations and interviews to collect data (Diaper and Stanton, 2004).

A full day concept-mapping workshop was held to structure the participants' knowledge of outdoor education and to visualize the main concepts in the domain and the relationships between the concepts. The two researchers in the workshop took the roles of facilitator and note-taker. The procedure was based on the 
approach of Novak and Cañas (2007). The mapping started with the question 'What is outdoor education?' This resulted in eighty-eight concepts that were written down on sticky notes; to bring some structure and order to these, one of the domain experts and the facilitator grouped them according to affinity. This produced an affinity diagram: that is, a categorization of notes that are similar and go together (Raven and Flanders, 1996; Scupin, 1997). The sticky notes were then put on a whiteboard and formed the draft of a concept map. Relations between diff erent concepts were identified. The resulting map was subsequently used as a shared frame of reference in two workshops where researchers and teachers jointly addressed the question of technology could be used in relation to the different concepts in the map.

Three prototypes of Minnesmark were built and evaluated in usability tests with thirteen teachers and nine participants who were not teachers. The fi nal editor was tested with fourteen teachers, three males and eleven females. That is a gender distribution that reflects the distribution in the staff. Their ages ranged from 28 to 58 years $(M=47.2, S D=10.2)$, and their teaching experience varied from 1 to 33 years $(M=17.9, S D=10.7)$. The participants in the test were asked to set up their own trail in the editor, and usability issues were noted.

Finally, in an evaluation of the VASS project, semi-structured phenomenographic group interviews (in pairs) were carried out with six primary and middle school teachers and twelve students from year 3 to 6 (ages 9 to 12). The selection of teachers was made by the project manager and that of the students by their teachers. The interviews, which were audio recorded, were at both the start and end of the project. A phenomenographic method comprises a qualitative and inductive approach where open questions are posed to obtain the recipients' conceptions of phenomena (Marton and Pong, 2005). The questions put to the teachers were: Why do you teach the way you do? How do you perceive students learn in and outside the classroom? What is your experience of and how do you feel about teaching and learning with the mobile technology, and what do you want the students to learn? What is your experience of the outdoor space as a learning environment? The interview questions to the students were: What is your experience of teaching and learning using the mobile technology? What is your experience of the outdoor space as a learning environment?

\section{Data Analysis}

Field notes from observations and interviews were analysed thematically by affinity diagramming (Raven and Flanders, 1996; Scupin, 1997). Hierarchical task analysis (Stanton et al., 2005) was used to analyse interaction and decisions by determining the overall goals of the participants' tasks, these were then broken down into subgoals, and operations that fulfil those subgoals. Plans used to fulfil the overall goals were identified.

The interviews were transcribed and analysed according to participants' conceptions of the use of mobile technology in outdoor education, which is a 
conventional approach in phenomenographic research (Marton and Pong, 2005). Statements made by the participants were interpreted and categorized, and meanings and variations in conceptions were noted. Interpretations were iterated with the teachers and validated in a group interview.

\section{Results}

The results section shows how digital mobile technology was used in the project to augment the landscape and places around the school, how the mobile augmented reality platform Minnesmark was used, and what the opportunities and challenges were teachers and students.

\section{Teaching Practices and Experiences}

The teachers did not know in advance exactly what they wanted the students to learn in their combination of outdoor education and new technology. The character of the project was to explore the possibilities of this way of working. The teachers, trained in traditional teaching approaches, acknowledged that they needed inservice training not only in new technologies, but also outdoor education.

\section{The Physical Surroundings}

The school was situated in an urban area with green surroundings and parks. The environments used for learning were, for example, the schoolyard, the green surroundings, and the town. One teacher described the role of the places in the following way:

The focus is on the place where the students, with their senses, are present. The narrative given in this place gives the special focus that is determined based on what you want the students to learn. The core of this, I believe, is in the outdoor educational thinking where the presence in the physical place gives an extra dimension.

The students and the teachers worked with the local area. For example, one teacher describes how they studied:

the traces we saw were left of agricultural land or of historical places such as Ramlösa brunn [a former health resort $1.3 \mathrm{~km}$ from the school]. What could it look like? Why is the stone fence located where it is?

The places they worked with gave rise to questions and aroused curiosity to fi nd out more, not only outdoors, but also when the students and the teachers came back 
to the classroom. Figure 2 depicts how two of the students solve an assignment in a forest near the school.

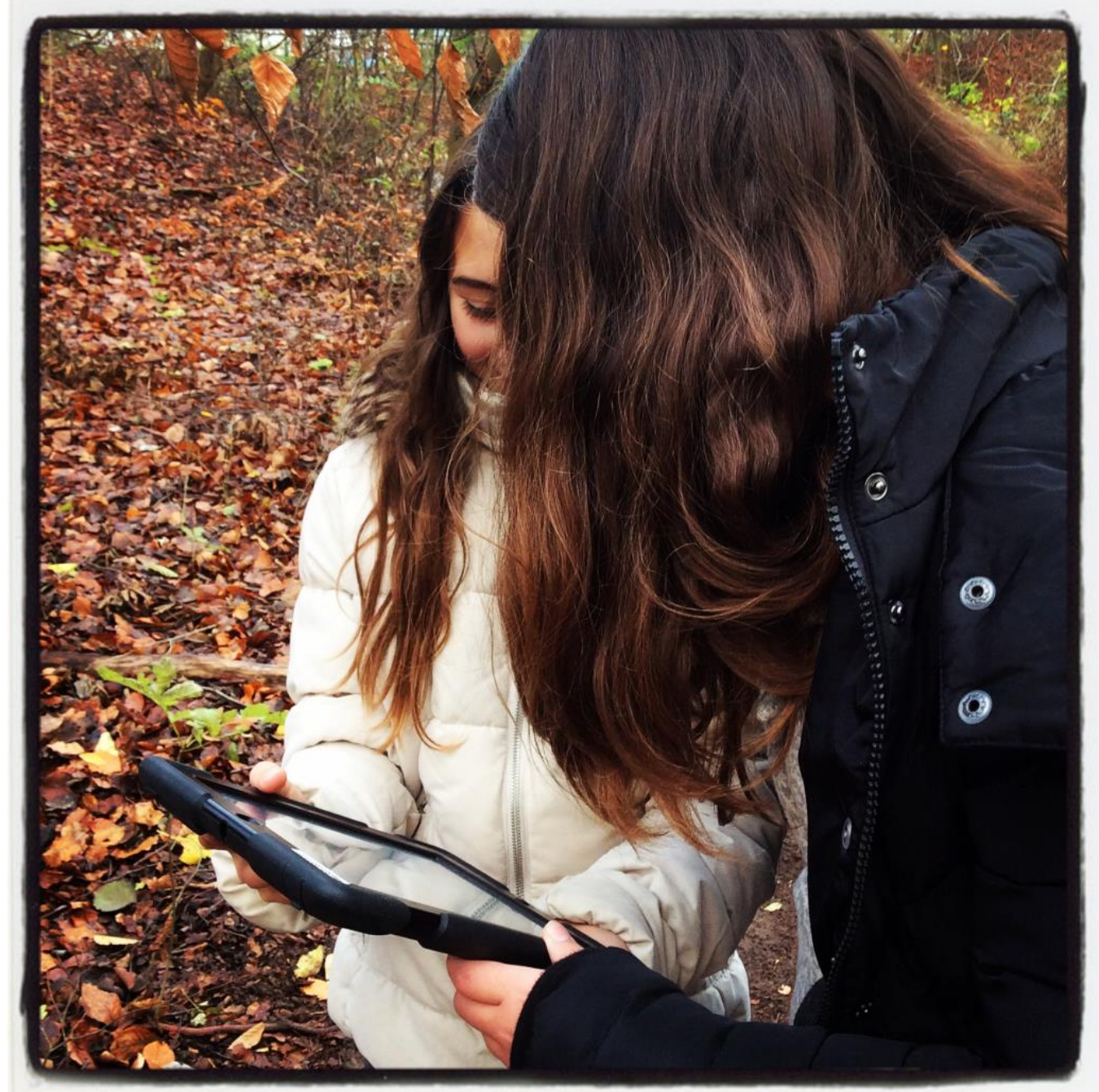

Figure 2. Two students solve an assignment in a forest near the school.

\section{Tablet Computers}

There was a very low ratio of students to computers at the school when the project started: approximately one stationary computer per fifteen students and the school had done no work at all with tablet computers. The teachers were also beginners when it came to doing school related work on mobile devices, but many students had their own smartphones at home. Tablets (Apple iPad) were purchased for the project.

The students used the tablets to take photos and record sound to accompany the photos. They could also search for places with the help of images and make stories about the places. The class also went outside to carry out assignments when working with the topic of the human body. They performed experiments that they 
filmed or photographed. Some assignments required a large space. For example, when the teacher gave the students the assignment to enact the movement of the Earth and the Moon around the Sun and film their enactment. In another class, the students went out to create art using natural materials connected to the outdoor places. The students then documented their work with the camera and sent it to the teacher who set it up in a slideshow.

\section{QR-Codes}

Lessons typically started in the classroom with, for example, stories from history like The Dacke War 1542-1543, or the Reformation and the Age of Discovery. The teacher also recorded these as short audio clips and linked them to a QR-code to be scanned. The QR-codes were placed along a forest trail close to the school where the students were used to walking. In this way, they rehearsed the stories they had heard in the classroom, and new questions could be asked both of and by the students. The students also took photos on site and shared them via Instagram and wrote answers to questions with a certain hashtag to gather them in the same place. One teacher noted that the QR-codes gave a sense of mystery or treasure that is opened to gain understanding. The learning objectives that the teacher had set were that the students were to be able to interpret the stories, discuss them, put their ideas about them into words, and explain those ideas in a group. In an e-mail, one teacher described how the technology could add new dimensions to the places that were the focus for learning:

\section{Each place and object can be assigned a story (fictional or factual) and the digital device can add parts to this story. Example: in each tree there is a transport of water during the growing season, which we have a very hard time seeing and experiencing. But through a digital tool this could be understood. And also, in place by the tree.}

\section{GPS Coordinates}

The teachers also collected GPS coordinates for important places close to the school, such as the milestone, the marl pit, the brook, the tree with hole, etc. These coordinates could then be used when they wanted to add places to the digital tools. The teacher could then use the technology to augment or load the places with photos and assignments, as, for example, estimating the height of the school, a distance, a circumference, or an area using their bodies. The students had to interpret the assignment they got at the place and discuss with each other to understand, and then argue for a solution. The teachers also used the GPS coordinates in geocaching treasure hunts, which facilitated discussions on and learning about direction, time, and distance. The teachers wrote down facts that explained something about the place (i.e., pollution, mining, or 'Who was Gisela Trapp?') and added the text to the geocache. One teacher observed that using 
geocaching and treasure hunts in learning requires the students to interpret and generalize:

\section{What strategies were successful the last time; how did we do; what} should we think about; what did we learn?

Another outdoor class focused on the archaeological find of Ötzi - The Iceman who lived about 5.300 years ago, and the natural environment in which he lived in compared with the nature of places around the students. The teacher's purpose was to clarify the theme (food, water, shelter and fire) for the students. The technology was again used to give instructions and assignments when the students arrived at specific places, and to document their experiences and thoughts using the camera, for joint reflection and follow-up in the classroom afterwards.

\section{Teachers' and Students' Experiences}

The students enjoyed and looked forward to the outdoor learning sessions. They showed clearly that assignments outside, in a different context and in a different place, motivated learning and a wish to understand more. The teachers' experiences were that learning outdoors with new technology required presentations in the classroom beforehand, to make sure that content, assignments, and expected achievement were clear to the students. It also required the teachers to think things through and to make adequate preparations to increase student safety when they are outside the school grounds. They also thought that the assignments needed to lead on to work carried out later in the classroom, where the students could find connections, strengthen experiences and terminology, and reflect.

Sometimes, the teacher did not go outside with the students. The tablet then mediated the work of the teacher who acted as an architect for the educational situation and all that should happen in the outdoor environment. One teacher described it in the following way:

\section{Depending on age and group, I as a teacher am more or less close to the students in the area we study. Based on the places that have been loaded with content, the students' meeting with the place is followed up in the classroom and prepared before it is time to go out to the chosen area.}

The teachers reported that sending students out in groups of two or three with one tablet worked best as groups of four or five tended to split into two smaller groups. It was also important to be clear about who was responsible for what when the students went outside. One teacher thought it was preferable to have control over the timetable for a large part of the school day, because of the time it took for all students to complete their outdoor assignments. She also noted that not all 
students needed to be sent out at the same time, and different groups could be given different assignments.

\section{Using Minnesmark to Augment the Landscape}

One of the new technologies used was the Minnesmark mobile AR-platform. Figure 3 shows a storyboard of how Minnesmark was to be used to augment the landscape and the places around the school. The system made use of both vision-based augmented reality (with markers) and position-based AR. This means that media events could be triggered both as the user pointed the camera of his or her mobile device to a visual marker and as the user came to a place, defi ned by a GPS position. The system had an editor which the teachers used to set up augmented trails, and a mobile application for iOS that students used to access the trails created by the teachers.
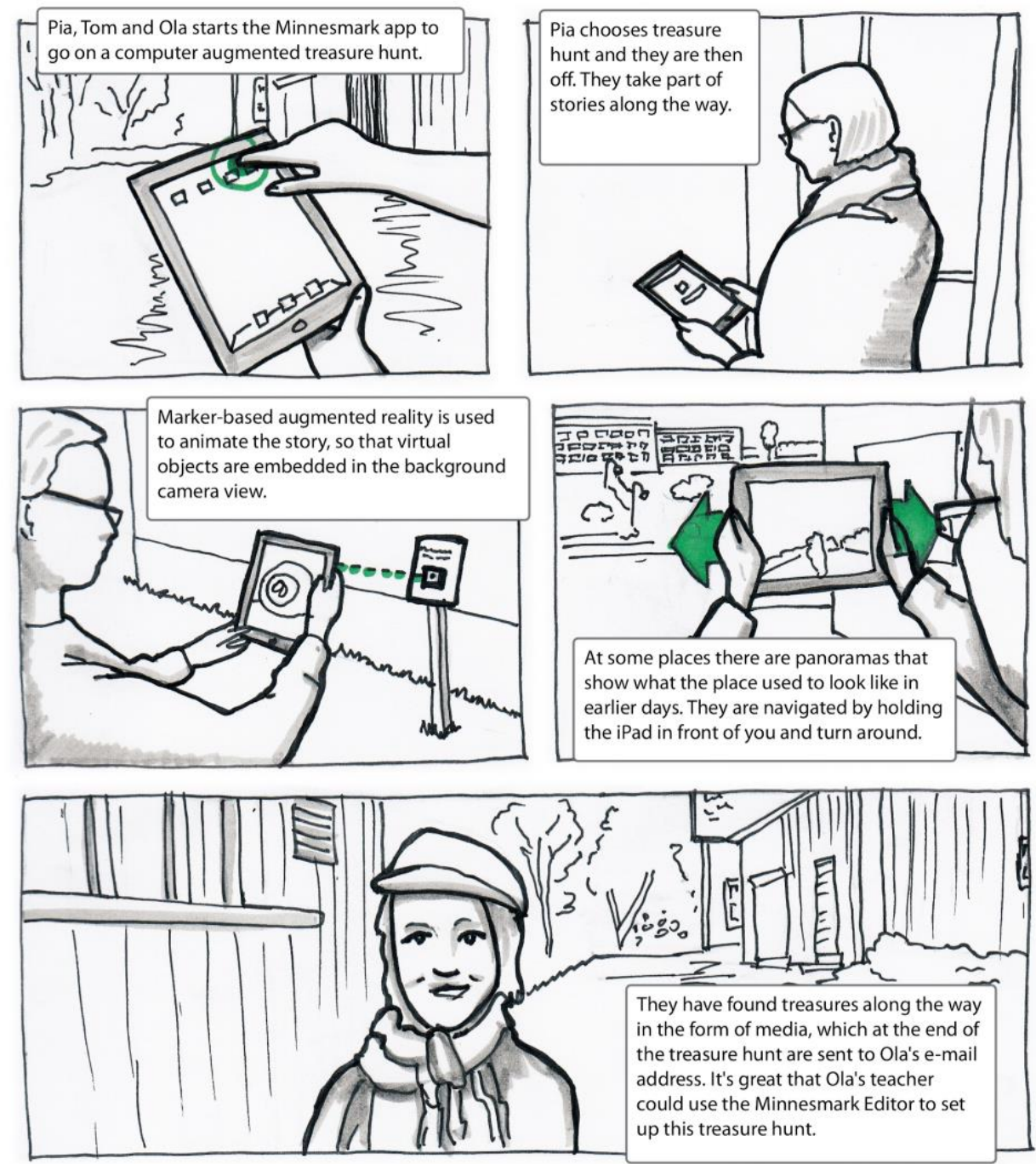

Figure 3. Storyboard for use of Minnesmark. (Source: Arvola, 2020) 
The computer-augmented trails had stations where students could be given the assignment of exploring the physical environment and access the media prepared by the teacher for that particular place. Media could include images, panoramas, movies, sound, and $3 \mathrm{D}$-objects. However, the teachers found it difficult to create panoramas and 3D-objects. At the end of the trail, 'treasures' in the form of media were sent to the students' or teachers' email, so that the students could take material back to the classroom for presentation or further work.

Figure 4 consists of photos that one of the teachers took of her students using Minnesmark. The last frame of shows an arrow on the tablet computer pointing to the next station. It also shows one empty circle representing one remaining station, and three Xs representing already visited stations.
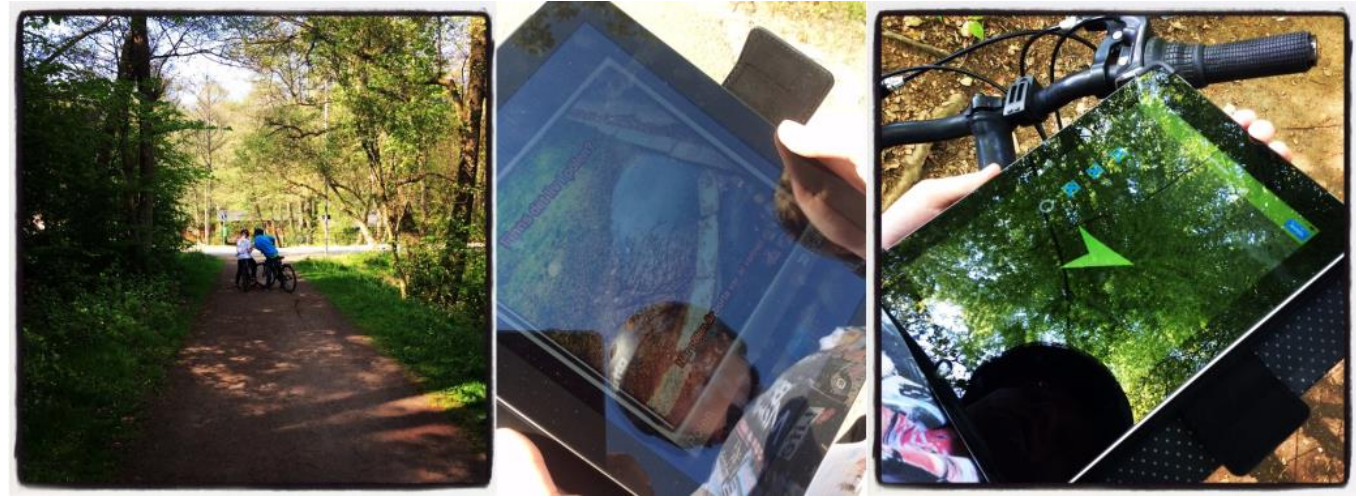

Figure 4. Students using Minnesmark on an iPad.

An example of an outdoor class that a teacher created with Minnesmark was a species inventory of bugs to gain a better understanding of the concept 'biodiversity', by connecting the abstract concept to concrete places. The students used the app to find the places and get their assignments. For example, in figure 5 it says, 'Are there any dragonflies here? What are they doing?'

Learning the role of diff erent trees in the nearby environment was another outdoor class that one of the teachers made with Minnesmark. Places were augmented with images and sounds triggered by GPS positions and markers, to prompt students to consider, for example, seasonal changes in those places.

The task analysis showed that an outdoor class could be divided into a preparation phase followed by the class itself and then post-class work. The class comprised one or several activities conducted serially or in parallel. Every activity began with an introduction to the assignment, sometimes the students being divided into smaller groups. This was followed by the main activity, with the students as the key actors. Activities could also include a final closing phase, which allowed them to reflect on the activity and tidy up the technology and materials that had been used. The teachers' preparations included planning both content and procedures for one or several classes. The post-class work focused on following up the class in relation to the learning objectives stated in the curriculum, and lessons learned. 


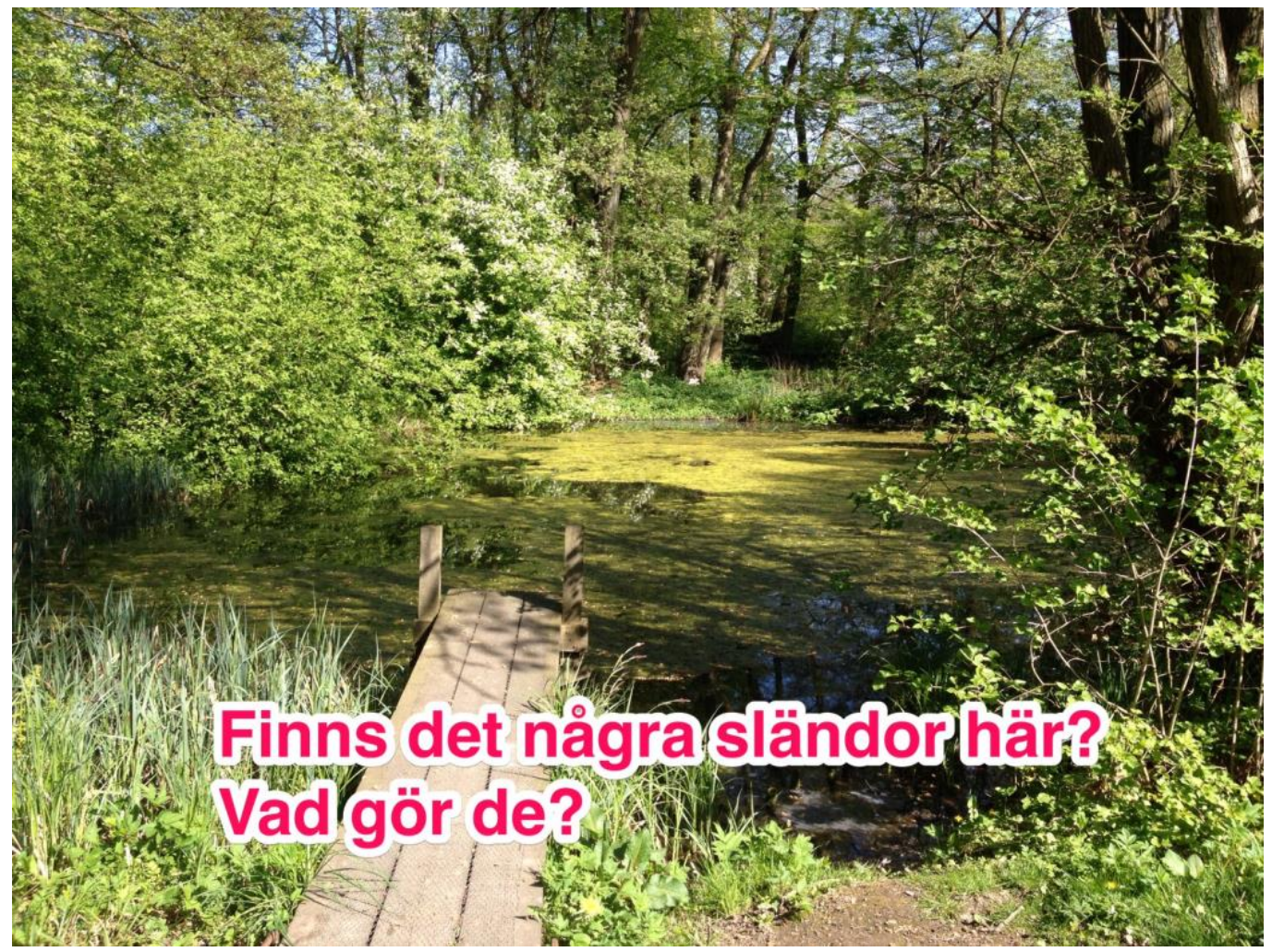

Figure 5. Screen from the pond where Minnesmark was used to ask students to spot dragonflies.

The students liked Minnesmark and found it easy to understand. The teachers appreciated the flexibility of choosing assignments and media to activate multiple modalities and senses. Many valued the simplicity of the editor. One said in the usability evaluation (Sylvan, 2015, p. 37): 'The program is clear, good that it is stripped. You understood where to find things, there weren't too many points.'

\section{Opportunities}

The opportunities of mobile augmented reality combined with outdoor education was described as follows by one of the teachers:

Think about the possibility of being on site, seeing how stone walls were built, and then trying to lift a stone from the wall. It provides a physical memory that can then be linked to the work on, for example, Sweden's agricultural society during the nineteenth century. Or to be in place in the forest and be able to see on the screen how the soil is worked under the forest litter by insects, worms, and fungi. 


\section{Favourable Conditions}

The results from the interviews before the educational intervention and the new technology were introduced show that most students already had a good understanding tablet computers and smartphones. They were not used to learning outside the classroom and were excited about it. The results from the follow-up interviews, carried out a year and a half later, show that in most cases the students felt that this 'new way' of learning through a combination of mobile technology and outdoor education gave new perspective on the learning. It was not something that could take place in a traditional classroom.

\section{Students' Reactions}

Meeting phenomena, processes, and objects for learning in an authentic environment outdoors, and then processing them in the classroom, was perceived by the students as increasing the possibilities for action, which strengthened the classroom context. Many students also explained that classmates who normally did not work very well in the classroom - 'the students who find it hard to stay still' got more scope for action in the outdoor environment.

The interaction between outdoors and classroom was perceived as creating a better learning environment for the whole group. It also emerged that both students and teachers found social and pedagogical gains in a clearer and more visible cooperation between students outdoors compared to learning in a classroom. Outdoors and indoors are perceived as being beneficial in different ways, and were expressed as:

\section{'You might get more facts indoors.' 'You get good breaks if you switch between outdoors and indoors because then you also get some fresh air.' 'I think it's a good idea, but you have to work for it.'}

Reading materials and facts that had been introduced in the classroom were often rehearsed outdoors using digital technology. One student refl ected about the fact that 'You probably learn more indoors, but also a bit outdoors, you have to collect factual information indoors and then develop it outdoors'. Or as another student said, 'it is also more fun to learn outdoors', without specifying reasons, but none of the students had the opposite perspective and enthusiasm for a new way of teaching certainly played a role. The outdoor sessions that the students referred to were in general about one hour two times per month in the immediate environment, often in the valley about 500 metres from the school.

\section{Teachers' Reactions}

The experience among the teachers was generally that the direct contact with the place and objects for learning increased the students' motivation in a way that made them interested enough to want to fi nd out more about the lesson content that was later reflected on in the classroom. The teachers felt that the younger students (age 
9 and 10) were more enthusiastic than the older ones (age 12). The content of lessons was mainly connected to the natural sciences (maths and natural sciences), but also to social sciences, primarily history, which the educational trails were constructed around.

\section{Technology Bridging Indoors and Outdoors}

Throughout this project the importance of the connection between the classroom and the outdoor space was key. Connecting different outdoor environments to the topics the students were working on in the classroom was central to the combination of new technology and outdoor education. The technology could bridge the national curriculum (why) and the work that happened in school, so that a particular topic (what) was connected to an actual learning activity (how) at a certain place (where) and time (when).

One opportunity was that augmentation of the landscape and places could help set the focus, pose questions and afford actions. It could help the teacher to send students out on missions. Mobile technology in general can be useful both for finding places and for informing about assignments. It can also be used to document and bring back material produced on site. Mobile technology can also tell students of what they should do when they reach the place. One teacher said:

It's easier to set the focus in the classroom. But there are so many impressions that catch the attention outdoors, and the technology can then help students to find a place, an assignment and content.

Another followed the same line of reasoning:

The technology can slow down the pace so that the students don't rush on. It can invite action by providing an assignment to perform. The students can discuss, explain and record.

The teachers stressed the fact that outdoor place-based sensory experience was important, and it was something the classroom could not offer. However, it was also important for the students and teachers to get an opportunity to discuss and reflect on their place-based experiences when back in the classroom.

\section{To See That Which Cannot Be Seen}

Another opportunity was that the augmentation of the landscape and places could render symbols and timelines visible. Sometimes places can be ascribed a new meaning, the teachers argued. The place is then used to tell the story that the teacher wished to tell. The augmentation could get houses and stones to speak. Often, however, places are already packed with meaning. Places symbolize something and have timelines. For example, in the local town square there is a story about a buried treasure from the seventeenth century. The augmentation could 
provide a point of entry to the context and the narrative. By entering a place or by scanning a marker, students could be introduced to the story of that place. It takes an expert or a guide to read the landscape, to look into the geology of the stone, or to see the photosynthesis in the tree. The augmentation could enable the students to see what otherwise remains unseen in a landscape or at a place. One teacher noted that the mobile augmented reality combined with outdoor education could do something that was difficult for the teacher in the classroom:

\section{To get more senses active in reading and understanding places. You are there, you see, you hear, you get the app screen to show, as in a window to what could have happened there before. We can get amplification using voices, sounds, music. So, we get several senses strengthened in reading the historical traces of the place, to see what has been, how it sounded, with sound.}

Technology could also facilitate conceptualization and reflection. An example of that was how students created miniature dioramas outdoors of which that they took photos. They then brought the photos indoors, projected them onto a wall and discussed them.

\section{Challenges}

\section{Organizational Issues}

The decision to combine outdoor education and mobile augmented reality had to be made together with the headmaster, because it required a plan on how outdoor education and new technology can be connected and used as natural components of teaching. Without such a plan any educational development remains with the individual teacher. Development of teaching methods also takes time for teachers for which they require day release, but in this project a major part of testing, doing, redoing, and improving ideas took place after the end of the working day.

\section{In-Service Training}

In the group of teachers, all were less experienced with the technology than the project leader. They expressed insecurity in how to use it in learning situations outdoors, and also how outdoor education and the use of mobile technology were going to be received by the students. They reported a lack of knowledge regarding where, when, what, how and why the landscape could be used as classroom and as teaching material. Teachers sometimes felt that they were in a didactic 'vacuum' outdoors, unable to connect the knowledge content, the subject, and the theme to the diff erent places for learning.

The insecurity among the students regarding the usefulness of the outdoor environment in learning was also expressed both in the first interview and in the 
follow-up. It became obvious during the student interviews that not all participating teachers had taken part fully in the outdoor learning situations together with the students. Instead, they stayed in school while the students carried out their learning assignments outdoors. This might be connected to individual teachers' ways of sett ing up their teaching.

\section{Preparations}

One of the teachers stressed the importance of producing content in advance and deciding what places to augment with that particular content. It was also important to think about connections to the learning objectives in the curriculum during the preparations. In addition, the procedures for the outdoors lesson had to be clear. One aspect of preparation was to figure out how the technology both offered and demanded structure. One of the teachers reported that she made a guide for herself for how to do things step-by-step, for example, how to connect coordinates to images and how to name files. Teachers also found that they had to give the students procedures to follow. The students had to learn how to learn outdoors using technology. The groups sent out (usually pairs or triads) also had to be composed of students who could work well together.

\section{Safety}

A safety concern, highlighted by one teacher, was when she sent students (age 1112) outside the school grounds without a teacher. She thought about the risk of being robbed of the tablet, forgetting about the traffic, or going off to buy sweets. All these things needed to be gone through several times in the classroom. Choosing places with safety in mind was important for this teacher. If something were to happen, then she thought that it would be better if the students were in groups of three rather than two. In other cultural contexts and other countries, having the students leave the school grounds without a teacher may be unthinkable.

\section{Discussion}

The research question was how to make use of mobile augmented reality in combination with outdoor education. For the teachers, early experiments involved trial and error, and opportunities and challenges in combining new technology and outdoor education. The students used the introduced technology in outdoor education by gathering information, taking photos, and recording sounds that they brought back to the classroom for further work, presentation, and reflection. The teachers also prepared films, sounds, and images that were displayed when students arrived at a place or directed the camera to a visual marker. These media also included assignments for the students to perform at that particular place. The teachers tried to build a story that connected classroom activities and outdoor activities. The students went out a couple of times per month in small groups with 
one tablet per group. Sometimes their teacher joined them outside and sometimes they performed the outdoor assignments by themselves. The usability the Minnesmark system was not a major issue for the teachers and students. The teachers' work included preparing and conducting outdoor classes (consisting of one or several activities), and post-class work.

Fägerstam (2012) proposed four central components to outdoor education: the concrete sensory experience; learning from the experience; the authentic learning place; and the reflection on the experience. The outdoor environment is complex and there are many aspects on which students can focus. By directing the students to the right place and providing them with place-specific instructions and assignments, the new technology helped highlight what to focus on. The possibilities to record and take photos of those things on which the teacher wanted the students to focus was also a means by which the teacher could focus the students' attention. Learning through the experience was facilitated by the new technology through the questions that teachers had prepared for the students, and repetition of stories that they had heard in the classroom helped solidify the learning. Instead of watching films and reading about things in the classroom, the technology made it possible to situate the content in the authentic place for the learning activity. Finally, since the students could bring recordings and photos back to the classroom, the technology also facilitated reflection on the experience, hence creating an interplay between outdoor activities and the classroom. Accordingly, the new technology affected all four of Fägerstam's components of outdoor education.

Opportunities included using digital mobile technologies and augmentation of places and landscapes to connect the outdoor and indoor environment, set focus, pose questions and afford actions, render symbols and timelines visible, provide a point of entry to the context and the narrative, and facilitate conceptualization. Challenges concerned how to make use of the landscape, producing or choosing content, structuring processes, setting up student groups, and aligning activities and content with learning objectives in the curriculum.

The opportunities and challenges can be connected to the stages of teachers' work with an outdoor lesson. In the preparation phase, the digital mobile technology can be expected to be used by the teacher to set things up. It is an advantage if the same material can be reused several times or if an earlier trail can be adapted since preparation time is scarce (Kljun et al., 2020). Inspirations and base material can also come from material shared by other teachers or created by students. It is an advantage if the technology assists in planning, for example by listing all the preparations and items needed. It was a challenge for the teachers to connect activities to learning objectives in the curriculum, and technology for outdoor education could also facilitate this connection, for example by structuring suggested and already prepared activities in relation to the curriculum. In the lesson phase, teachers could give different outdoor assignments to different parts of the class to allow for more time with certain groups. 
An insecurity that remained at the end of the project concerned where, when, what, how and why outdoor pedagogical land use can be integrated as classroom and teaching material. Some teachers handled it successfully, while others struggled. Some teachers found it difficult to connect the knowledge content to the different places for learning in a clear way. The question of how to use the outdoor places in the local area in, for example, science (e.g. alkalis and acids) or social science (e.g. countries in Europe) is not trivial. It requires a creative way of viewing and reading the landscapes in relation to the contents of curriculum. In this project, we also introduced new technologies that in addition required the teachers to rethink their teaching methods even further. It is therefore not surprising that some of the participating teachers struggled.

The results can also be related to the requirements identified by Dunleavy and Dede (2014). Their requirements include possibilities for teachers and students to set up and edit vision-based and location-based augmented reality experiences; maps, user archives and libraries of re-usable digital objects; abilities to link to media on the web; possibilities of assigning different participants to different roles; different ways of triggering digital objects; ability to set up assessments and assignments, saving data, managing device-to-device communication; and integration with social networks. We could observe the need for all of these in our study. The Minnesmark system offered both editor and browser for vision-based and location-based AR. The editor, but not the browser, had maps, but there were no libraries of re-usable objects. This became an issue due to the time and skills it took to create content. Our system did not allow links to media on the web - it would have been beneficial if it had. Minnesmark had two ways of triggering digital objects: position and visual marker and setting up assignments were never a problem. Assessments of students' performance was not a requirement in our study, and neither was device-to-device communication. The teachers explored having the students upload things to social media platforms and that was one way of saving data.

The most important feature of the technologies used in combination with outdoor education, was that digital objects and multimedia could be embedded, so that virtual objects were overlaid onto the physical environment. Through this feature, augmented landscapes and places could support the development of understanding of complex phenomena, provide sensory experience, set a context, and set the focus in outdoor education. Using the position of the device to trigger an event is a feature that we observed could support contextualization and set the focus for the learning activity. A potential additional feature is to use location-based functionality for safety, by tracking the positions of students and sending messages in real time.

However, not everything has to be built into a digital system. Take for example assigning students different roles. This can be done just as well in written or face-toface instructions, which was the approach of the teachers in our study. Furthermore, all functionality does not need to be covered in one application. For 
example, standard applications on the tablet or the phone offer the possibility of taking notes, taking photos, and making audio recordings. There is no need to include such features in an application like Minnesmark, since the students can switch to the camera app to document and then switch back to Minnesmark. The same applies to social networking features. Eliasson (2013) argues that it is a good idea to have different functionality for each mobile device to allow students to assume different roles, but again, this does not have to be built into the technology and can be managed through procedures.

\section{Limitations}

This research project provided an exploration of how technologies have been used and perceived by a small group of teachers and students at a primary school in a midsized Swedish city. Even though data triangulation, researcher triangulation, and participant validation have been employed, the study suffers from the same strengths and limitations as similar studies. The teachers involved owned the research question and the knowledge interest. This means that their enthusiasm may be unwarranted. In action research, this is seen as a guarantee of relevance, but it also means that generalizations and the transfer of results should be made carefully, bearing the contextual factors of the project in mind. The results show how outdoor educational practices can be approached, but it is probably not the way this is done by all teachers.

\section{Future Research}

So far, we have not investigated the details of interaction between students, teachers and technologies in outdoor education, but it would be worthwhile pursuing such a study. Such a study requires different research methods to those of the present study. It also requires a clear focus at the start, which did not fi t with our explorative purpose. Detailed analysis of video-recorded multimodal interaction between students, teachers, and technologies is very time consuming, but it would also be rewarding (e.g. Goodwin, 2018). Such a study would be able to pinpoint the fi ne-grained facets of the methods, including methods mediated by technology, that students and teachers use to make sense of the places and the content for learning.

A question that arises in our reading of the state-of-the-art research (our own included) concerns the impacts on learning of augmented landscapes and places in outdoor education. To answer that question, an experimental or quasi-experimental setup is necessary. One earlier study showed that one particular mobile augmented reality application could have positive learning effects in particular outdoor natural science learning activities (Liu et al., 2009). Earlier research thus indicated the potential value of mobile augmented reality in outdoor education and our explorations provided further evidence of this. Central questions that remain are: what role does the place have as basis for explanation to the variation in the results 
of learning; what role do the teaching methods play; and what role does the mobile technology play? Making pedagogical use of the landscape augmented by digital mobile technology is, however, also a competency issue. The knowledge about how to vary learning environments and how they interact needs to be increased. We do not yet know when to stay in the classroom and when to go out, and we do not know when to use one outdoor environment instead of another. How teachers can compose students' movements between different outdoor and indoor places to facilitate learning remains an open question.

\section{Conclusions}

The project started in a set of issues and aims that our results address. We saw that the teachers could use the mobile augmented reality combined with outdoor education to make the outdoor environment meaningful for the students' learning by storytelling that weaved the outdoor space and classroom space together. Outdoor learning places and technology were used to widen the students' awareness of the local environment surrounding their school. The teachers and the students used the technology to unite facts about nature, society, and sustainable development that the students had read in their textbooks with built and natural places in their local area. All in all, the project made use of mobile augmented reality to make places in the local environment, outside the classroom context, a starting point to increase the authenticity of the teaching.

\section{References}

Arvola, M., Blomkvist, J., Holmlid, S. and Pezone, G. (2012) A service walkthrough in Astrid Lindgren's footsteps, in Tossavainen, P. J., Harjula, M. and S. Holmlid (eds.) ServDes.2O12 Conference Proceedings Co-Creating Services, The 3rd Service Design and Service Innovation Conference. Linköping: Linköping University Electronic Press.

Arvola, M. and Holm, A. (2014) Device-orientation is more engaging than drag (at least in mobile computing), in V. Roto, V., Häkkilä, J., Väänänen-Vainio-Matt ila, K., Juhlin, O., Olsson, T., and Hvannberg, E. (eds.) Proceedings of the 8th Nordic Conference on Human-Computer Interaction: Fun, Fast, Foundational (NordiCHI '14). New York: ACM.

Billinghurst, M. and Dünser, A. (2012) Augmented reality in the classroom. Computer, 45(7), pp. 56-63.

Bouvin, N.O., Brodersen, C., Hansen, F.A., Iversen, O.S. and Nørregaard, P. (2005) Tools of contextualization: extending the classroom to the fi eld, in Eisenberg, M. 
and Eisenberg, A. (eds.) Proceedings of the 2005 Conference on Interaction Design and Children (IDC'O5). New York: ACM.

Dahlgren, L.-O. and Szczepanski, A. (1998) Outdoor Education: Literary Education and Sensory Experience. Linköping: Kinda Education Centre.

Diaper, D. and Stanton, N. (2004) The Handbook of Task Analysis for HumanComputer Interaction. Mahwah, NJ: Lawrence Erlbaum.

Dillon, J., Rickinson, M., Teamey, K., Morris, M., Choi, M.E., Sanders, D. and Benefi eld, P. (2006) The value of outdoor learning: evidence from research in the UK and elsewhere. School Science Review, 87(320), pp. 107-111.

Ducasse, Julie (2020) Augmented reality for outdoor environmental education, in Geroimenko, V. (ed.) Augmented Reality in Education. Cham: Springer.

Dunleavy, M and Dede, C. (2014) Augmented reality teaching and learning, in Spector, J.M., Merrill, M.D. Elen, J. and Bishop, M.J. (eds.) Handbook of Research on Educational Communications and Technology. New York: Springer.

Eliasson, J. (2013) Tools for Designing Mobile Interaction with the Physical Environment in Outdoor Lessons. Doctoral dissertation, Stockholm University.

Fägerstam, E. (2012) Space and Place: Perspectives on Outdoor Teaching and Learning. Linköping: Linköping University.

Faskunger, J., Szczepanski, A. and Åkerblom, P. (2018) Teaching with the Sky as a Ceiling: A Review of Research About the Significance of Outdoor Teaching for Children's Learning in Compulsory School. Linköping: Linköping University Electronic Press.

FitzGerald, E., Adams, A., Ferguson, R., Gaved, M., Mor, Y. and Thomas, R. (2012) Augmented reality and mobile learning: the state of the art, in Specht, M., Sharples, M. and Multisilta, J. (eds.) CEUR Workshop Proceedings 955, International Conference on Mobile and Contextual Learning 2012 (mLearn 2012).

Georgiou, Y. and Kyza, E.A. (2018) Relations between student motivation, immersion and learning outcomes in location-based augmented reality settings. Computers in Human Behavior, 89, pp. 173-181.

Goodwin, Charles (2018) Co-operative Action. Cambridge: Cambridge University Press.

Hansen, F.A., Kortbek, K.J. and Grønbæk, K. (2010) Mobile urban drama for multimediabased out-of-school learning, in Angelides, M., Lambrinos, L., Rohs, M. 
and Rukzio, E. (eds.) Proceedings of the 9th International Conference on Mobile and Ubiquitous Multimedia (MUM '10). New York: ACM.

Henrysson, A., Billinghurst, M. and Ollila, M. (2005) Face to face collaborative AR on mobile phones, in Fourth IEEE and ACM International Symposium on Mixed and Augmented Reality (ISMAR '05). Los Alamitos, CA: IEEE Computer Society.

Huang, T.-C, Chen, C.-C. and Chou, Y.-W. (2016) Animating eco-education: to see, feel, and discover in an augmented reality-based experiential learning environment. Computers \& Education, 96, pp. 72-82.

Jeng, Y.-L., Wu, T.-T., Huang, Y.-M., Tan, Q., and Yang, S.J.H. (2010) The add-on impact of mobile applications in learning strategies: a review study. Educational Technology \& Society, 13(3), pp. 3-11.

Kljun, M., Geroimenko, V. and Čopič Pucihar, K. (2020) Augmented reality in education: current status and advancement of the field, in Geroimenko, V. (ed.) Augmented Reality in Education. Cham: Springer.

Klopfer, E. and Squire, K. (2008) Environmental detectives - the development of an augmented reality platform for environmental simulations. Educational Technology Research and Development, 56(2), pp. 203-228.

Koutromanos, G., Tzortz oglou, F. and Sofos, A. (2018) Evaluation of an augmented reality game for environmental education: 'Save Elli, Save the Environment', in Mikropoulos, T. (ed.) Research on E-Learning ICT in Education. Cham: Springer.

Liu, T.-Y., Tan, T.-H. and Chu, Y.-L. (2009) Outdoor natural science learning with an RFID-supported immersive ubiquitous learning environment. Educational Technology \& Society, 12(4), pp. 161-175.

Løvlie, L. (2007) The pedagogy of place. Nordic Studies in Education, 27(1), pp. 32-37.

Marton, F. and Pong, W.Y. (2005) On the unit of description in phenomenography. Higher Education Research \& Development, 24(4), pp. 335-348.

Nilsson, S., Arvola, M., Szczepanski, A. and Bång, M. (2012) Exploring place and direction: Mobile augmented reality in the Astrid Lindgren landscape, in Farrell, V., Farrell, G., Chua, C., Huang, W., Vasa, R. and Woodward, C. (eds.) Proceedings of the 24th Australian Computer-Human Interaction Conference (OzCHI '12). New York: ACM.

Novak, J.D. and Cañas, A.J. (2007) Theoretical origins of concept maps: How to construct them, and uses in education. Reflecting Education, 3(1), pp. 29-42. 
Nouri, J. and Cerratto-Pargman, T. (2015) Characterizing learning mediated by mobile technologies: a cultural-historical activity theoretical analysis. IEEE Transactions on Learning Technologies, 8(4), pp. 357-366.

Raven, M.E. and Flanders, A. (1996) Using contextual inquiry to learn about your audiences. SIGDOC Asterisk Journal of Computer Documentation, 20(1), pp. 1-13.

Rogers, Y., Price, S., Fitzpatrick, G., Fleck, R., Harris, E., Smith, H., Randell, C., Muller, H., O’Malley, C., Stanton, D., Thompson, M. and Weal, J.M. (2004) Ambient wood: designing new forms of digital augmentation for learning outdoors, in Druin, A. (ed.) Proceedings of the 2004 Conference on Interaction Design and Children: Building a Community (IDC'O4). New York: ACM.

Schmalstieg, D. and Wagner, D. (2007) Experiences with handheld augmented reality, in 6th IEEE and ACM International Symposium on Mixed and Augmented Reality (ISMAR '07). Los Alamitos, CA: IEEE Computer Society.

Schneider, J. and Schaal, S. (2018) Location-based smartphone games in the context of environmental education and education for sustainable development: fostering connectedness to nature with Geogames. Environmental Education Research, 24(11), pp. 1597-1610.

Scupin, R. (1997) The KJ method: A technique for analyzing data derived from Japanese ethnology. Human Organization, 56(2), pp. 233-237.

Smørdal, O., Liestøl, G. and Erstad, O. (2016) Exploring situated knowledge building using mobile augmented reality. Qwerty - Open and Interdisciplinary Journal of Technology, Culture and Education, 1, pp. 26-43.

Sollervall, H., Otero, N., Milrad, M., Johansson, D. and Vogel, B. (2012) Outdoor activities for the learning of mathematics: Designing with mobile technologies for transitions across learning contexts, in IEEE Seventh International Conference on Wireless, Mobile, and Ubiquitous Technology in Education. Los Alamitos, CA: IEEE Computer Society.

Stanton, N.A., Salmon, P.M., Rafferty, L.A., Walker, G.H., Baber, C. and Jenkins, D.P. (2013) Human Factors Methods: A Practical Guide for Engineering and Design. Farnham: Ashgate.

State Education and Environment Roundtable (2000) The Effects of Environmentbased Education on Student Achievement. San Diego, CA: State Education and Environment Roundtable.

Sylvan, S. (2015) Introduktion av nya verktyg för utomhuspedagogik:

Bakomliggande faktorer för upplevd användbarhet [Introduction of new tools in 
outdoor learning: underlying factors for perceived usability]. Bachelor's project Linköping University.

Szczepanski, A. and Andersson, P. (2016) Perspectives on place: 15 professors' perceptions of the importance of the place for learning and teaching outdoors, in Tuszyń ska, L. (ed.) Koncepcja zrównowazonego rozwoju: Wksztalceniu nauczycieli klas poczatkowych. Warszawa: Wydamnictwo Akademii Pedagogiki Specijalnej.

Whyte, W.F. (1991) Participatory Action Research. Newbury Park, CA: Sage.

Wu, S., Chang, A., Chang, M., Yen, Y.-R. and Heh, J.-S. (2010) Learning historical and cultural contents via mobile treasure hunting in Five-Harbor District of Tainan, Taiwan, in 6th IEEE International Conference on Wireless, Mobile, and Ubiquitous Technologies in Education. Los Alamitos, CA: IEEE Computer Society.

Zimmerman, H.T. and Land, S.M. (2014) Facilitating place-based learning in outdoor informal environments with mobile computers. TechTrends, 58, pp. 7783.

\section{Acknowledgements}

This study was made possible through a research grant from the Marcus and Amalia Wallenberg Foundation (MAW 2012.0042). We wish to thank Anna Holm for assisting with data collection and analysis; Umapathi Rao Tallapragada, Richard Wandel, Ante Wall, Emanuel Kinberger, and Tina Danielsson for programming; Christian Söderberg for graphic design; Sebastian Sylvan, Jonatan Andersson, Adam Annerhult, David Eriksson, Jonna Magnusson, and Emelie Molinder for conducting usability evaluations; and Eva Ragnemalm for valuable comments on drafts.

Keywords: Interaction design; Augmented reality; Outdoor education; Landscape; Place-based learning 